\title{
RELAÇÃO ENTRE A PROTEÍNA DE CHOQUE TÉRMICO E O ESTRESSE TÉRMICO EM FRANGOS DE CORTE
}

\author{
RELATIONSHIP OF HEAT SHOCK PROTEIN AND HEAT STRESS IN BROILERS
}

\author{
Boschini, C. ${ }^{1 *}$, Gonçalves, F.M. ${ }^{1}$, Catalan, A.A.S. ${ }^{1}$, Bavaresco, C. ${ }^{2}$, Gentilini, F.P. ${ }^{3}$, \\ Anciuti, M.A. ${ }^{3}$ e Dionello, N.J.L. ${ }^{1}$
}

${ }^{1}$ Programa de Pós-graduação em Zootecnia/DZ/FAEM. Universidade Federal de Pelotas. Pelotas-RS. Brasil. *boschini.carolina@gmail.com

${ }^{2}$ Departamento de Zootecnia/FAEM. Universidade Federal de Pelotas. Pelotas-RS. Brasil.

${ }^{3}$ Instituto Federal Sul-rio-grandense. Campus CAVG. Pelotas/RS. Brasil.

\section{PalavRas chave adicionais}

Qualidade de carne. Termorregulação. Termotolerância.

\section{RESUMO}

Devido aos avanços em melhoramento genético e nutrição, o frango de corte atual atinge elevados índices de desempenho produtivo em um curto período de produção, resultado de um aumento nas taxas metabólicas das linhagens de crescimento rápido. Entretanto, sua capacidade termorreguladora permanece ineficiente, principalmente sob condições de altas temperaturas (acima de $35^{\circ} \mathrm{C}$ ) e umidade. Por conseqüência, as células respondem ao estresse pela expressão das proteínas de choque térmico ou heat shock proteins (HSPs), as quais funcionam como chaperonas moleculares, protegendo as membranas contra os radicais livres formados em situações de estresse. A exposição dos animais ao estresse no início da vida (pré-embriogenese) permitiria que o gene que regula a síntese de HSP70 seja sensibilizado favorecendo uma rápida expressão e síntese desta proteína em situações de estresse térmico, tornando 0 animal termorresistente a temperaturas elevadas. Além do ambiente (temperatura e umidade) outros fatores como, genética, nutrição e sanidade, também predispõem ao estresse do frango durante sua produção. Porém, se respeitadas as condições ambientais exigidas por estes animais, a exposição ao estresse será reduzida. Como conseqüência final da resposta fisiológica a um estresse térmico, observa-se a depleção das reservas de glicogênio muscular no momento do abate, prejudicando as reações post mortem que con-

\section{Additional KEYWORDS}

Meat quality. Thermoregulation. Thermotolerance. tribuem para a qualidade de carne. Esta condição tem sido relacionada principalmente a um $\mathrm{pH}$ ácido, com redução da capacidade de retenção de água e diminuição da maciez da carne, favorecendo a formação da carne tipo PSE (pálida, mole e exsudativa), recusada pelo consumidor. Por isso os animais termotolerantes são mais resistentes, o que reduz o índice de mortalidade do lote. Desta forma, o presente artigo de revisão propõe-se esclarecer aspectos relacionados aos mecanismos envolvidos na resposta ao estresse térmico por calor em frangos de corte, enfatizando a contribuição das HSPs em tal situação contribuindo para a produção de uma carne de melhor qualidade e adequada aos padrões exigidos pelo mercado consumidor.

\section{SUMMARY}

Due to advances in breeding and nutrition, modern broiler chicken reaches a satisfactory growth performance in a short time because fast growing breeders are showing a more rapidly metabolism, however, the ability to regulate body temperature still remain inefficient under high environment temperatures (above $35^{\circ} \mathrm{C}$ ) and humidity. In this case, cells promote a stress response that allows the expression of heat shock proteins (HSPs) witches has the prime molecular function as chaperones, protecting cells against the damages caused by free radicals 
produced during stress situations. When animals are exposed to stress in early life (preembryogenesis) the HSP70 gene is activated and the protein is expressed and synthesized more quickly when the chicken are exposed later in life to high environment temperature, became thermo resistance. Besides the environment (temperature and humidity) other factors such as genetics, nutrition and health, also predispose stress in chickens during production period. However, if all conditions of welfare were respected, the probability of a stress exposure is reduced in lower level. As final physiologic consequence of heat stress exposure, it can be observed a glycogen muscle depletion during slaughtering, affecting post mortem reactions that contributes to meat quality. This condition has been related to a lower $\mathrm{pH}$, with a reduction in capacity of water retention, and a decrease in meat tenderness, favoring the formation of meat type PSE (pale, soft and exudative), which is not pleasing to the consumer. So, animals with heat tolerance are more resistant to high environment temperatures, reducing mortality of a considering part of the lot. According to described above, this review article will related some issues related to termic stress response of broilers emphasized HSPs contribution for a better meat quality as final product to attend costumer and market demands.

\section{INTRODUÇÃO}

O frango de corte moderno consiste em um animal de produção geneticamente aprimorado para rápido crescimento e deposição de tecido muscular, características obtidas devido a avanços genéticos e nutricionais aplicados. Contudo, o metabolismo dessas aves ficou mais acelerado, e sua capacidade termorreguladora é ineficiente sob condições de alta temperatura e umidade (Lagana, 2005). Por conseqüência, as células do organismo desses animais respondem a este estímulo ambiental de várias formas, destacando-se a resposta ao choque térmico também referida como resposta ao estresse térmico (Welch, 1992). Tal resposta permite a rápida expressão de uma classe de proteínas conhecidas como heat shock proteins (HSPs) (Locke e Noble, 1995; Fehrenbach e
Niess, 1999), essenciais para a sobrevivência de células expostas a um agente ambiental estressante (Welch, 1992). A importância das HSPs para a homeostase celular esta relacionada ao fato destas proteínas constituírem uma classe altamente conservada, desde procariotos até o homem (Meyer e da Silva, 1999).

Existe HSPs com diferentes pesos moleculares e estas estão divididas em famílias, onde as mais estudadas são as proteínas que apresentam pesos moleculares de $60,70,90$ e $110 \mathrm{Kda}$, que por serem encontradas em ampla variedade de organismos, são denominadas HSPs principais (Kiang e Tsokos, 1998).

As HSPs mantêm as proteínas recémsintetizadas em uma conformação que favorece sua translocação, auxilia a sua ligação a proteínas não-ativas durante o estresse celular (Fink, 1999), auxilia no transporte de proteínas através das membranas mitocondriais e a interação com receptores de esteróides (Gabriel, 2001). Por estas características, as HSP 70 são conhecidas como chaperonas moleculares (Welch, 1992; Essing e Nosek, 1997) (figura 1). Estudos sobre a HSP70 e seus efeitos sobre o organismo, comprovam que a aquisição de termotolerância, está relacionada com aumentos nos níveis dessa proteína (Parsell e Lindquist, 1994).

Um fenômeno largamente estudado é a tolerância obtida através de tratamentos por curtas exposições a temperaturas elevadas os quais conduzem à síntese de um pequeno número de HSPs (Parsell e Lindquist, 1994). Manipulações térmicas em estágios muito precoces da vida das aves, onde a regulação da temperatura corporal e mecanismos de feedback ainda estão imaturos, causam alterações no limite da resposta termorregulatória (Arjona et al., 1988, Yahav, 2000). Uma mudança na temperatura corporal pode ser imposta pelo ambiente ou internamente, ajustando-se o setpoint termorregulatório. O conceito setpoint termorregulador reside na influência 


\section{PROTEÍNA DE CHOQUE TÉRMICO E O ESTRESSE TÉRMICO EM FRANGOS}

recíproca dos sensores de frio e calor sobre o sistema controlador da temperatura corporal. Quando fora da faixa ótima de temperatura, ocorre massivo acúmulo tanto de proteínas recém-sintetizadas quanto de proteínas pré-existentes (Morimoto et al., 1994).

O presente artigo de revisão propõe-se esclarecer aspectos relacionados aos mecanismos envolvidos na resposta ao estresse térmico por calor em frangos de corte, enfatizando a contribuição das HSPs em tal situação.

\section{TERMORREGULAÇÃO}

Setenta e oito por cento da massa corporal da maioria dos vertebrados é água e muitas das reações químicas que liberam energia ou que sintetizam novos compostos ocorrem em um meio aquoso contendo uma

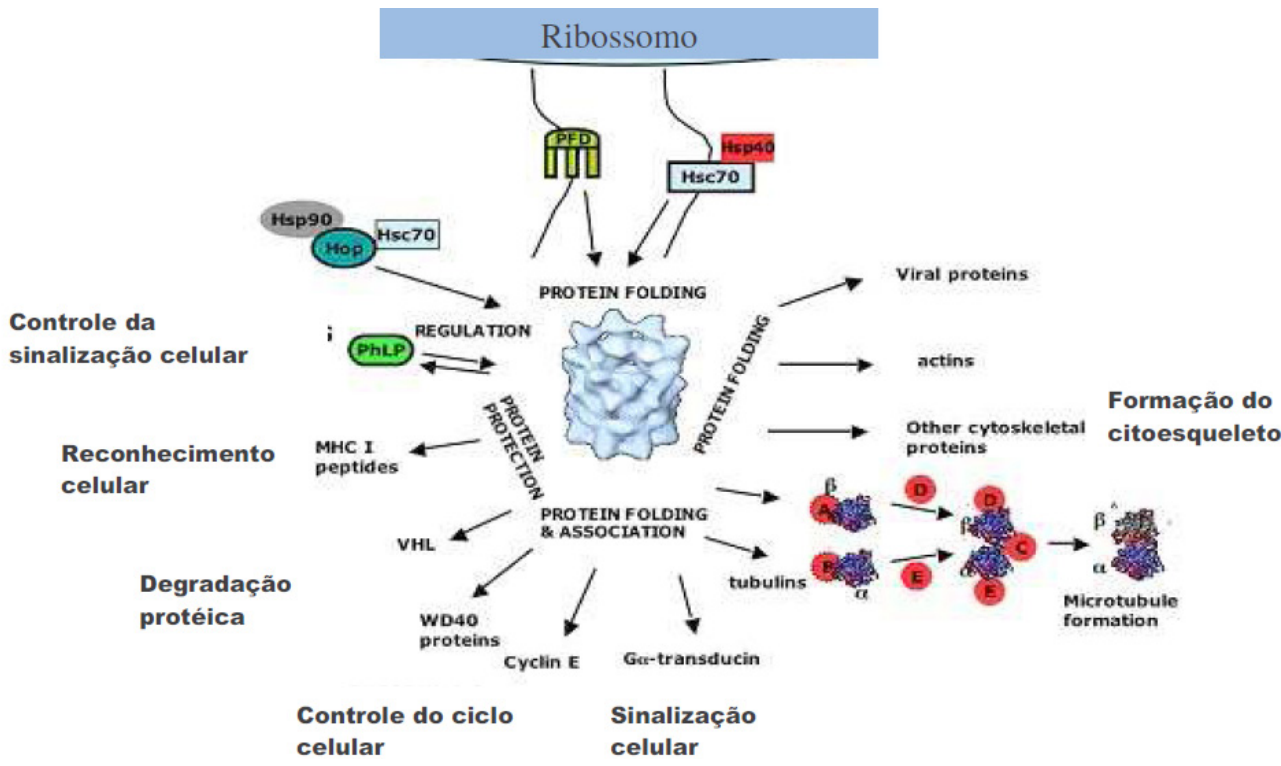

Figura 1. Ilustração demonstrando os processos onde atuam as chaperonas, citando Hsc70 (Hsc70 sinônimo para Hsp70) e Hsp90, seus ligantes e algumas co-chaperonas como a Hop - Hsp90 organizing protein, um sinônimo para STI1. São citadas as principais funções das chaperonas e alguns processos onde elas agem. As principais funções são: dobramento de proteínas, dobramento e associação de proteínas e proteção de proteínas. Estas funções estão intimamente ligadas a eventos biológicos, como: controle da sinalização celular, reconhecimento celular (célulacélula e célula-matriz extracelular), degradação de proteínas (processamento de proteínas), controle do ciclo celular e sinalização celular. (Adaptado de www.cnb.uam.es/.../index_html.jpgfig/ image). (Illustration showing the processes where the chaperones act, citing Hsc70 (Hsc70 synonym for Hsp70) and Hsp90, their ligands and some cochaperones such as Hop - Hsp90 organizing protein, a synonym for STI1. Are mentioned the main functions of chaperones and some processes where they act. The main functions are: protein folding, protein folding and association and protection of proteins. These functions are closely linked to biological events, such as control of cell signaling, cell recognition (cell-cell and cell-extracellular matrix), protein degradation (protein processing), cell cycle control and cell signaling. (Adapted from www.cnb.uam.es/ .../index_html.jpgfig/image). 
complexa mistura de íons e outros solutos. A temperatura é um fator crítico na função dos organismos, pois todas as reações bioquímicas são sensíveis a ela. Em geral, as taxas de reações aumentam à medida que a temperatura aumenta, mas nem todas as reações apresentam esta mesma sensibilidade (Pough et al., 2009).

Aves animais são endotermos que regulam sua temperatura corpórea por meio de mecanismos que equilibram a produção metabólica de calor e a perda deste para o ambiente, produzindo calor metabólico derivado da taxa metabólica basal ou de repouso, pela alimentação e pela atividade dos músculos esqueléticos (Pough et al., 2009). Como geralmente vivem sob condições de temperatura ambiente menor que a temperatura corporal, a perda de calor para o ambiente é uma circunstância mais usual do que o ganho do mesmo. O equilíbrio da perda de calor é, portanto, uma das funções reguladoras mais importantes, e aves empregam sua plumagem de um modo muito efetivo como isolante contra a perda de calor (Pough et al., 2009).

Esse ajuste de temperatura é papel do sistema homeostático e, quando acionado, manterá a temperatura corporal dentro dos limites toleráveis, permitindo a constância do meio interno e o perfeito funcionamento dos sistemas (Furlan e Macari, 2002).

A percepção da temperatura é medida pelos termorreceptores periféricos e unidades termossensíveis no sistema nervoso central. Sua ação conjunta parece ser necessária para obter a regulação máxima da temperatura contra o calor e o frio (Anderson, 1984).

\section{MECANISMOS DE TERMORREGULAÇÃOENDOTÉRMICA}

A temperatura do corpo e a taxa metabólica precisam ser consideradas simultaneamente para entender como animais endotermos, como as aves, mantêm suas temperaturas corpóreas em um nível estável face às variações da temperatura ambiental.

Cada espécie de endotermo tolera uma amplitude delimitada de temperatura do ambiente acima da qual a temperatura do corpo pode ser mantida estável através do uso de ajustes fisiológicos e posturais para a perda e produção de calor. Esta amplitude de temperaturas ambientais é denominada de zona de tolerância. Acima desta zona, a capacidade do animal dissipar calor é inadequada e, tanto a temperatura do corpo como a taxa metabólica aumentam à medida que a temperatura ambiental aumenta, até que o animal morra devido ao calor. Em temperaturas ambientais situadas abaixo da zona de tolerância, a capacidade do animal de gerar calor a fim de equilibrar a perda de calor é ultrapassada, a temperatura do corpo diminui, a taxa metabólica declina e resulta em morte pelo frio (Anderson, 1984; Pough et al., 2009).

Condições de conforto térmico ou termoneutralidade preconizam um ambiente térmico adequado. Para as atividades de mantença e produção as aves geram certa quantidade de calor, sendo indispensável manter uma temperatura ambiente favorável, para que a ave atinja sua atividade vital e, consequentemente, seu potencial genético (Tinôco, 2001). Segundo Smith (1964) zona de conforto corresponde à faixa de temperatura ambiente de criação, na qual a resposta animal ao ambiente é positiva e a demanda ambiental é conciliada com a produção basal, acrescida da produção de calor equivalente à atividade normal e do incremento calórico da alimentação. Nesta zona, o animal alcança seu potencial máximo, e a temperatura corporal é mantida com a mínima utilização de mecanismos termorregulatórios.

Rosemberg et al. (1974) descreveram a zona de conforto térmico como a zona de indiferença térmica, em que apenas o metabolismo normal favorece a energia necessária para manter a temperatura corporal no nível normal, ou seja, é nesta faixa que o animal mantém sua temperatura cor- 


\section{PROTEÍNA DE CHOQUE TÉRMICO E O ESTRESSE TÉRMICO EM FRANGOS}

poral constante. A zona de conforto ou termoneutra varia de acordo com a espécie e dentro da mesma espécie animal. Nas aves, a zona termoneutra muda com a constituição genética, idade, sexo, tamanho corporal, peso, dieta, estado fisiológico, exposição prévia ao calor (aclimatação), variação da temperatura ambiente, radiação, umidade e velocidade do ar (Abreu et al., 2000).

\section{FATORES GENÉTICOSE AMBIENTAIS PREDISPONENTESAO ESTRESSE NA PRODUÇÃO DE FRANGOSDE CORTE}

\section{GENÉTICA}

Ainda que todas as linhagens avícolas desenvolvidas objetivem melhores resultados de desempenho, é essencial a otimização de fatores inerentes ao ambiente onde são produzidas, respeitando as exigências da linhagem de escolha. Respostas comportamentais, fisiológicas e metabólicas a situações aversivas estão relacionadas à constituição genética e experiência prévia dos animais a tais situações (Terlouw, 2004). O efeito negativo sobre a taxa de crescimento é maior em frangos com alto potencial genético para crescimento rápido em comparação a frangos com taxas menores para este parâmetro (Cahaner e Leenstra, 1992).

Lu et al. (2007) avaliaram a resistência de duas linhagens de frangos submetidas à uma condição de estresse térmico verificando uma diferença significativa entre a resposta de ambas genéticas, evidenciando que, em parte, a resposta às adversidades e desafios impostos pelo ambiente onde os animais são criados, é modulada de acordo com a constituição genética da linhagem. Neste mesmo sentido, ao compararem duas linhagens de frangos de corte submetidas a duas condições ambientais distintas, Hernandes et al. (2002) observaram uma maior indução na expressão de HSPs em uma das linhagens, constatando influência da genética sobre a expressão de determinados genes.

\section{TEMPERATURA AMBIENTAL}

Excetuando a fase incial de produção de frangos de corte, a qual exige temperaturas elevadas $\left(31 \mathrm{a} 33^{\circ} \mathrm{C}\right)$, a exposição de frangos temperaturas já é bem reconhecido como um dos fatores ambientais que influenciam a produtividade dos animais de produção. Entretanto, já foi constatado que a exposição de frangos de corte a altas temperaturas aos cinco dias de idade favorece a viabilidade destes animais quando desafiados com altas temperaturas aos 42 dias de idade (Yahav e Hurwitz, 1996), pois permite uma resposta adaptativa a uma exposição prévia ao agente estressor.

A expansão de indústrias avícolas para regiões de altas temperaturas, como no centro-oeste, também foi acompanhada por uma maior preocupação ao que se refere às práticas de manejo nos aviários. A manipulação severa associada ao estresse térmico por calor constitui em uma associação desfavorável ao desempenho produtivo das aves.

Al-Alqil e Zulkifli(2009) verificaram que frangos de corte produzidos em galpões convencionais abertos, os quais apresentam oscilações de temperatura, desenvolvem maior expressão da HSP 70, suportando o estresse térmico por calor durante o transporte com melhor eficiência em comparação a frangos criados em aviário fechado com ambiente controlado. Tal constatação sugere que os animais desafiados constantemente pelo meio adverso, desenvolvem maior tolerância a um grau mais aversivo de estresse térmico por calor, considerando que a faixa ótima de temperatura ambiente para frangos, apartir dos 21 dias de idade, a temperatura ótima está na faixa de $24^{\circ}$, decrescendo até $16^{\circ} \mathrm{C}$ aos 56 dias de idade (Cobb, 2008).

\section{NuTRIÇÃO}

A nutrição responde por, aproximada- 
mente, $70 \%$ dos custos despendidos em um sistema de produção animal. Desta forma, o aproveitamento dos nutrientes nela contidos deve ser suficiente para que ocorra um retorno econômico de tal investimento. Neste sentido, uma nova ciência está sendo desenvolvida objetivando determinar o quanto uma dieta pode influenciar a expressão, ou não, de determinados genes; a nutrigenômica. Estudos nesta área podem revelar informações sobre marcadores específicos a serem utilizados para monitorar a condição de saúde de animais submetidos a uma condição alimentar em específico. Zulkifli et al. (2000) determinaram que a restrição alimentar promove maior secreção da HSP 70, verificando que o manejo alimentar exerce influência sobre a expressão de determinados genes. Já Figueiredo et al. (2007) verificaram que a restrição alimentar por um período de 16 horas não influenciou a expressão gênica da HSP 70. A contradição nos resultados é válida e comprova a máxima de que a interação genótipo e ambiente é responsável pela expressão ou supressão de genes em um indivíduo.

Objetivando integrar temperatura e nutrição, Sahin et al. (2002) verificaram que a adição de $250 \mathrm{mg}$ de vitamina $\mathrm{E} / \mathrm{kg}$ de ração melhora significativamente o desempenho de frangos de corte criados sob condições de estresse térmico por calor, evidenciando que determinados nutrientes exercem efeito benéfico quando adicionados em níveis ótimos nas dietas em condições ambientais de alta temperatura.

De acordo com Borges et al. (2003), um dos métodos utilizados para o controle do estresse calórico é a manipulação química do equilíbrio ácido-básico das aves através de compostos como o bicarbonato de sódio, cloreto de potássio, cloreto de cálcio e cloreto de amônia adicionados à água ou na ração. Entretanto, Salvador et al. (1999) não observaram diferenças significativas no desempenho de frangos de corte submetidos a estresse calórico e suplementa- dos com bicarbonato de sódio na ração e na água.

\section{SANIDADE}

A resposta ao estresse mediada pelas HSPs é uma das respostas adaptativas mais altamente conservadas (Moseley, 2000). Apesar de sua nomenclatura, vários outros fatores, além do calor, podem estimular a secreção destas proteínas (Hernandes et al., 2002). Neste sentido, foram descritos três mecanismos principais de ativação do sistema imune mediados por diversas proteínas relacionadas ao estresse, principalmente HSP70, HSP90 e GP96. O primeiro envolve o aparecimento da HSP70 na superfície de células tumorais ou infectadas por vírus, o segundo está relacionado à habilidade do complexo proteína-peptídeo do estresse a estimular a resposta do linfócito T citotóxico contra as células que produzem este complexo (Moseley, 2000).

Algumas pesquisas indicaram que as HSPs possuem a habilidade de modular a resposta imune celular, onde em situação de estresse térmico por calor, a HSP70 localizada no núcleo celular, se agrega a elementos responsáveis pela síntese de RNA prevenindo a expressão e secreção de proteínas anormais (Lee, 1992; Franco-Jimenez e Beck, 2007).

Sob condições de temperatura elevada, o frango direciona a energia utilizada para seu crescimento à manutenção da temperatura corporal dentro da normalidade, evitando ao máximo a resposta ao estresse térmico e assegurando a função orgânica dos tecidos dentro dos limites fisiológicos (Lin et al., 2006). Entretanto, em grau mais elevado de exposição, ocorre alterações em parâmetros imunológicos, como a relação heterófilo:linfócito (H/L), um importante indicador de estresse em aves domésticas. Al-Murrani et al. (1997) verificaram que a relação $\mathrm{H} / \mathrm{L}$ pode ser utilizada como um critério para seleção de aves resistentes à altas temperaturas, favorecendo os sistemas de produção localizados em regiões 


\section{PROTEÍNA DE CHOQUE TÉRMICO E O ESTRESSE TÉRMICO EM FRANGOS}

de clima tropical.

\section{CONDIÇÕES AMBIENTAIS PARA EVITAROESTRESSETÉRMICO}

Para obter o máximo desempenho produtivo na avicultura é importante oferecer aos animais condições ambientais adequadas, evitando principalmente altas temperaturas. Conforme Fabrício (1994) o estresse por calor é responsável por grandes perdas no rendimento dos lotes de frangos, ocorrendo aumento de mortalidade e piora na conversão alimentar, além de diminuição do peso corporal, especialmente quando as condições estressantes ocorrem na fase final, próximo ao abate. Em trabalho realizado por Oliveira Neto et al. (2000), foi constatado que frangos submetidos a estresse por calor na fase final de produção, obtiveram uma menor média para o peso final, quando comparado às aves em termoneutralidade, $1684 \mathrm{~g}$ e $1857 \mathrm{~g}$, respectivamente.

Liew et al. (2003) analisando os efeitos da restrição alimentar e o acondicionamento térmico, sob a expressão da HSP70, observaram que apesar das aves apresentarem o peso corporal semelhante aos 42 e 49 dias de idade, sendo este o período em que foram submetidas ao estresse térmico, os tratamentos que sofreram restrição alimentar e estresse térmico apresentaram maior ganho de peso quando comparados com os demais.

O que se preconiza para as aves adultas é a temperatura ambiente de $21,1^{\circ} \mathrm{C}$, a umidade relativa em torno de $50 \%$, a renovação de ar deve ocorrer em menos de 1,3 min. e a velocidade máxima do ar deve estar entre 2,29 e 2,41 m/s-1 (Barnwell e Rossi, 2003). Entretanto, dificilmente estes valores são encontrados em condições comerciais de produção, sobretudo no verão. Por isso alguns cuidados no manejo devem ser realizados para minimizar ou evitar o estresse térmico das aves. Pois, segundo Figueiredo (2006), as HSP's são, aparen- temente, induzidas por estresses moderados, os quais não são necessariamente letais, a fim de proteger o organismo contra estresses ainda mais severos.

Existem poucas granjas, no Brasil, com ambiente controlado e falar de temperatura ambiente na criação de frangos de corte implica também nas variações climáticas do país. Assim como outras variáveis devem ser levadas em conta, como microclima regional, linhagem, idade, peso, tipo de ração, manejo, histórico das aves e tipo de construção utilizada na granja (Furlan e Macari, 2002).

A capacidade das aves em suportar o calor é inversamente proporcional ao teor de umidade relativa do ar. Quanto maior a umidade relativa do ar, mais dificuldade a ave tem de remover calor interno pelas vias aéreas, o que leva ao aumento da freqüência respiratória em até 10 vezes.Todo esse processo que a ave realiza no sentido de manutenção da homeotermia promove modificações fisiológicas que podem comprometer seu desempenho (Oliveira et al., 2006). De acordo com Barbosa Filho (2004) aves que foram submetidas a diferentes sistemas de criação e a duas condições ambientais, conforto e estresse, os animais apresentaram alterações nesta variável fisiológica, onde no sistema de conforto cama +ninho a freqüência respiratória ficou em torno de 160 a 180 movimentos por minuto, já para a condição de criação em gaiolas foi em torno de 180 a $200 \mathrm{mov} / \mathrm{min}$. Para a condição ambiental de estresse as médias foram de 260 a $280 \mathrm{mov} / \mathrm{min}$ em cama+ninho e 300 a $320 \mathrm{mov} / \mathrm{min}$ para condição de criação em gaiola.

Para Nääs (1997) na maioria das regiões produtoras do Brasil, somente a ventilação natural não é suficiente para manter lotes pesados dentro da região de termoneutralidade, necessitando de ventilação forçada. A palavra ventilação não deve ser considerada apenas um ato, mas sim um processo no qual devem ser consideradas variáveis, como clima, tamanho e densidade 
do lote e tipo de instalação (Macari et al., 2004).

O aumento da velocidade do ar em um aviário, via ventilação forçada, tem sido utilizado como um meio para reduzir o estresse calórico das aves, em condições de altas temperaturas associadas a altas umidades relativas, pois melhora a habilidade das aves em dissipar calor por convecção (Macari et al., 2004).

Conforme Tinôco (2004), a melhor proteção contra a insolação nas instalações avícolas é a natural, utilizando a sombra das árvores. Porém, recomenda-se o uso de árvores altas para não prejudicar a ventilação no interior dos galpões. Já um bom material para cobertura das instalações precisa apresentar temperaturas superficiais amenas. Os telhados podem ser de isopor entre duas lâminas de alumínio, sapê e compensado, sendo que os mais utilizados são os de alumínio simples, barro, amianto e chapa zincada ou ferro galvanizado.

Também é possível utilizar forros sob a cobertura, como uma segunda barreira física, resultando em melhores condições de conforto térmico para as aves (Abreu et al., 2007).

\section{TERMOTOLERÂNCIA}

Uma das abordagens que tem mostrado resultados promissores é a estimulação precoce das aves a altas temperaturas, sendo que esse estresse na fase inicial pode ter impacto considerável em relação à fisiologia e comportamento do animal (Liew et al., 2003). Complementando isso, Figueiredo (2006) diz que quando o manejo nas instalações não é suficientemente eficiente para minimizar os prejuízos com lotes sob estresse, uma alternativa seria estimular os embriões, ainda no incubatório, a termotolerância. A capacidade de sobrevivência de diferentes indivíduos de uma mesma espécie quando expostos a temperaturas extremas por curtos períodos de tempo (termotolerância) varia grandemente, sendo tal habilidade dependente de fatores genéticos e ambientais. A termotolerância se desenvolve principalmente devido a expressão e acúmulo altamente regulado de várias HSP's na célula, levando à ativação de mecanismos de reparo macromoleculares, como uma estratégia de defesa contra desafios subseqüentes (Figueiredo, 2006).

Outra possibilidade, conforme Yahav et al. (1997) seria expor as aves com cinco dias de idade a $36^{\circ} \mathrm{C}$, durante 24 horas, para promover certa resistência caso sofra estresse térmico quando adulta. De acordo com Basilio et al. (2001) frangos de corte submetidos a altas temperaturas aos cinco dias de idade apresentaram maior peso vivo em comparação aos não expostos. O acondicionamento térmico de frangos de corte machos a altas temperaturas na primeira semana de vida, também reduz a temperatura corporal de animais produzidos em ambientes tropicais (Basilio et al., 2003), podendo ser utilizada como estratégia para a prevenção do estresse térmico por calor em regiões de clima quente.

\section{ESTRESSE TÉRMICO E SUAS IMPLICAÇÕESNA QUALIDADE DA CARNE DE FRANGOS DE CORTE}

Devido aos avanços em melhoramento genético e nutrição, o frango de corte atingiu um desempenho produtivo impressionante com um metabolismo mais acelerado (Lagana, 2005). No entanto, sua capacidade termorreguladora parece ser deficiente para enfrentar condições de altas temperaturas e umidade, demonstrando que os animais selecionados para alto desempenho não são tão adaptados ao ambiente em que vivem como eram seus antepassados (Classen, 2000).

A qualidade da carne é dependente de características inerentes ao animal, da influência ambiental, de variáveis relacionadas ao manejo de produção e das condições de abate. As condições climáticas afetam diretamente o metabolismo 


\section{PROTEÍNA DE CHOQUE TÉRMICO E O ESTRESSE TÉRMICO EM FRANGOS}

das aves comprometendo a manutenção da homeotermia. Esse desequilíbrio fisiológico causado pelas variações de temperatura, tem efeito direto sobre as reservas de glicogênio muscular no momento do abate, responsáveis pelo desenvolvimento das reações post mortem (Petracci et al. 2001), que determinarão a qualidade da carne. Aves estressadas usam rapidamente suas reservas de glicogênio, o que pode resultar em seu esgotamento in vivo, impossibilitando a queda do $\mathrm{pH}$ post mortem, ou ainda, sofrem uma aceleração da glicólise, logo após o abate, gerando acúmulo de ácido lático no músculo, com conseqüente diminuição acelerada do pH (Mckee e Sams, 1998). Esta condição tem sido relacionada a um pH final mais baixo (Sandercock et al., 1999), com redução da capacidade de retenção de água (Sandercock et al.,1999; Petracci et al., 2001), e diminuição da maciez da carne (Petracci et al., 2001).

Offer e Knight (1988) afirmam que a queda de $\mathrm{pH}$ post mortem altera a composição celular e extracelular das miofibrilas, reduzindo a capacidade de reter água nas proteínas musculares. Isso é uma conseqüência da desnaturação protéica, especialmente da miosina. Uma vez desnaturada, a proteína perde suas características físicoquímicas e, conseqüentemente, a eficiência de ligação com as moléculas de água tornase bastante prejudicada.

\section{Atributos da CARNE}

Os principais atributos da qualidade de carne de aves são aparência, textura, suculência, sabor e propriedades funcionais, sendo a aparência e a textura os atributos que mais influenciam a seleção do consumidor na hora da compra e satisfação final do produto.

Holm e Fletcher (1997) estudaram a ifluência do estresse térmico sobre parâmetros de qualidade de carne em frangos e observaram que um estresse de 12 horas, antes do abate, induziu um $\mathrm{pH}$ final abaixo do normal, uma menor de perda de peso por cocção (PPC), assim como um aumento da rigidez da carne de peito de frango (Petracci et al., 2001).

Sandercock et al. (2001), com o objetivo de caracterizar as respostas fisiológicas e analisar a qualidade de carne de aves expostas a um estresse agudo, realizaram um estudo com dois tratamentos: controle $\left(21^{\circ} \mathrm{C}\right.$ e $50 \%$ UR) e estresse térmico agudo $\left(32^{\circ} \mathrm{C}\right.$ e $75 \%$ UR), ambos em câmara climática por duas horas. Os pesquisadores encontraram maior perda de peso por gotejamento e forte efeito do estresse térmico sobre a taxa de queda do $\mathrm{pH}$ post mortem do músculo, sugerindo uma aceleração do metabolismo glicolítico perimortem em aves estressadas. Em nenhum dos estudos descritos acima, os pesquisadores encontraram alteração na escala de cor da carne do peito.

A cor da carne de frango pode ser afetada por diversos fatores, como idade, sexo, linhagem, dieta, gordura intramuscular, localização anatômica do músculo, atividade física, condições de manejo pré-abate, como estresse térmico, e também em decorrência de problemas no processamento, como temperatura de escaldagem e condições de armazenamento e congelamento (ContrerasCastillo, 2001; Fletcher, 2002).

Os resultados de avaliação dos parâmetros de qualidade observados na literatura, portanto, evidenciam que o estresse térmico, sofrido por frangos de corte no período pré-abate, geram consequências negativas sobre o $\mathrm{pH}$, que tende a ser inferior na carne de animais estressados. Com isso, os frangos de corte podem sofrer desnaturação protéica e redução da capacidade em reter água nas proteínas musculares.

A baixa capacidade de retenção de água pode ser verificada nos valores elevados de perda de peso por cocção e perda de peso por gotejamento, uma característica indesejável para produtos cárneos, já que esse tipo de produto apresenta rendimento deficiente e pouca suculência. Além disso, as taxas mais elevadas de força de cisal- 
hamento contribuem para a redução da qualidade desse tipo de carne, isso porque apresenta menor potencial proteolítico post mortem, o que leva a uma diminuição da maciez (Brossi et al., 2009).

A oxidação lipídica é uma das maiores causas de deterioração da qualidade da carne, contribuindo para degradação do flavor e redução da vida útil dos produtos devido à iniciação da peroxidação (Vercellotti et al., 1992). Porém, segundo Brossi et al. (2007), o estresse térmico induzido de frangos de corte, em câmara climática por duas horas a aproximadamente $35^{\circ} \mathrm{C}$ e $75 \%$ de umidade relativa, não provocou alteração química detectada pela análise de TBARS (substâncias reativas ao ácido tiobarbitúrico) em músculo da sobrecoxa, refrigerada durante um, sete ou 14 dias de armazenamento. Esses resultados sugerem que a análise de TBARS realizada na carne in natura pode não ter a mesma sensibilidade que quando realizada no sangue ou fígado, ou ainda, que os efeitos desse perfil de estresse aplicado não apresentaram variação quanto à oxidação lipídica na carne.

A produção de níveis excessivos de espécies reativas ao oxigênio, enquanto o animal está vivo, pode ser estimulada por condições estressantes ou clínicas, resultando em distúrbios no balanço entre oxidação e os sistemas antioxidantes de defesa, causando peroxidação lipídica e injúrias oxidativas às proteínas do DNA (Dröge, 2002). Em frangos o balanço entre a produção de espécies reativas ao oxigênio e sistemas antioxidantes pode ser afetado pelo estresse térmico (Lin et al., 2000; Mahmoud e Edens, 2003).

\section{CARNe PSE}

Os atributos das características de qualidade de carne em animais estressados são sem dúvida, afetados de maneira irreversível para processamento e consumo in natura. A perda da funcionalidade da carne do peito de frango está associada à síndrome PSE (palid, soft, exsudative). Esse tipo de carne, por sua cor pálida e, principalmente por sua propriedade de não reter água, como um músculo normal, causa transtornos à industrialização. Ela apresenta rendimento deficiente, quando processada, dificuldade em manter sua própria água, baixa absorção de salmoura durante a marinação (Woelfel et al., 2002), perda de líquido por gotejamento (exsudação) na embalagem, baixa capacidade de emulsificação, pouca coesividade e perda de peso pós-cocção. Com isso, observa-se reduzida suculência (Fletcher, 2002), além de menor vida útil do produto (Barbut, 2002).

Alguns trabalhos evidenciaram que a incidência da ocorrência de carne PSE é maior no verão, demonstrando a influência do calor para a ocorrência do fenômeno (Mccurdy et al., 1996; Bianchi et al., 2007). Segundo Woelfel e Sams (2001) a incidência de carne PSE pode chegar até 50\% do total de carne obtida dependendo do período do ano e manejo.

\section{IMPORTÂNCIADAEXPRESSÃODA PROTEÍNA DE CHOQUETÉRMICO (HSP) EM FRANGOS PARA A AQUISIÇÃO DETERMOTOLERÂNCIA \\ E SUAS IMPLICAÇÕES PARA A QUALIDADEDACARNE}

A resposta ao estresse mediada pelas HSP's é uma das respostas adaptativas mais altamente conservadas. Em organismos unicelulares, a resposta ao estresse confere tolerância a uma variedade de perturbações que alteram a síntese protéica (Moseley, 2000). Este fenômeno de tolerância é também extremamente importante em organismos multicelulares, resultando em termotolerância e em resistência a diferentes tipos de estresse. Dessa forma, se os animais forem expostos a um período de estresse térmico, já nos primeiros dias de vida ou mesmo no desenvolvimento embrionário, o gene que codifica a proteína HSP será 


\section{PROTEÍNA DE CHOQUE TÉRMICO E O ESTRESSE TÉRMICO EM FRANGOS}

ativado, e então ocorrerá a síntese e expressão da proteína durante as mudanças bruscas de temperatura que possam ser um risco para a manutenção da homeotermia da ave, de forma a não alterar o metabolismo para que aquelas não venham a sofrer prejuízos em seu desempenho produtivo e posteriormente seu produto possa ser obtido com qualidade.

Arjona etal. $(1988,1990)$; Yahav e Hurwitz (1996), que induziram o estresses térmico em frangos de corte, machos, no início da vida, verificaram que houve um aumento na sobrevivência dos frangos na fase adulta sob alta temperatura ambiente. Isso comprova que os animais que sofrem estresse no início da vida, são mais resistentes as alterações de temperatura no final do ciclo.

Assim, as aves resistentes ao estresse, no momento pré-abate, não usarão rapidamente suas reservas de glicogênio, impedindo a aceleração da glicólise in vivo, a qual gera o acúmulo de ácido lático no músculo, com conseqüente diminuição acelerada do pH (Mckee e Sams, 1998). Sem a queda brusca do $\mathrm{pH}$ post mortem a ocorrência de carne do tipo PSE, com baixa capacidade de retenção de água e alta taxa de gotejamento pode ser muito menor.

Pouco se sabe sobre a influência da aquisição da termotolerância de frangos de corte ao estresse agudo, na qualidade da carne. Collin et al. (2007) estudaram os efeitos da manipulação termal durante os períodos pré e pós-embriogênese na termotolerância e características do múscu-

\section{BIBLIOGRAFIA}

Abreu, P.G., Baeta, F.C. Abreu, V.M.N., Soares, P.R., Perdomo, C.C. e Silva, M.A. 2000. Desempenho produtivo e bioeconômico de frangos de corte criados em diferentes sistemas de aquecimento. Rev. Bras. Zootecn., 29: 159-167.

Abreu, P.G., Abreu, V.M.N., Coldebella, A., lo do peito em frangos de corte e verificaram uma relação negativa entre $\mathrm{pH}$ post-mortem e perda por gotejamento, sendo que no grupo controle (que não recebeu manipulação termal) o $\mathrm{pH}$ post-mortem foi alto e a perda por gotejamento foi baixa e nos grupos que receberam manipulação termal pré e pós-embriogênese foram obtidos $\mathrm{pH}$ post-mortem baixo e perda por gotejamento alta. A partir desses resultados os autores constataram que a manipulação termal influenciou de forma negativa a qualidade da carne do peito de frangos de corte.

\section{CONCLUSÃO}

Através desta revisão de literatura, conclui-se que o estresse térmico é um fator preocupante na produção de frangos de corte e está associado a fatores genéticos e ambientais. Assim, o controle de temperatura, umidade e ventilação dentro do ambiente do aviário, bem como o balanceamento correto das dietas e o manejo adequado dos animais, são medidas simples para evitar o estresse das aves e posteriores perdas na qualidade de carne. A estimulação da expressão da HSP70 no período de pré-embriogênese, pode ser útil para reduzir os desafios de estresse térmico por calor que os frangos venham a ser submetidos durante o período de produção, através da aquisição da termotolerância, o que reduz a taxa de mortalidade e uma possível melhora na qualidade de carne, promovendo melhores resultados ao produtor, indústria e satisfação do consumidor.

Jaenisch, F.R.F. e Paiva, D.P. 2007. Condições térmicas ambientais e desempenho de aves criadas em aviários com e sem o uso de forro. Arq. Bras. Med. Vet. Zootec., 59: 1014-1020.

Al-Aqil, A. and Zulkifli, I. 2009. Changes in heat shock protein 70 expression and blood characteristics in transported broiler chickens 
as affected by housing and early age feed restriction. Poultry Sci., 88: 1358-1364.

Al-Murrani, W.K., Kassab, A., Al-Sam, H.Z. and AlAthari, A.M.K. 1997. Heterophil/lymphocyte ratio as a selection criterion for heat resistance in domestic fowls. Brit. Poultry Sci., 38: 159-163.

Anderson, B.E. 1984. Regulação da temperatura e fisiologia ambiental. In: Dukes, M.J.S. (Ed.). Fisiologia dos animais domésticos. Cap. 45. Editora Guanabara. Rio de Janeiro/RJ. pp. 623629.

Arjona A.A., Denbow D.M. and Weaver Jr., W.D. 1988. Effect of heat stress early in life on mortality of broilers exposed to high environmental temperatures just prior to marketing. Poultry Sci., 67: 226-231.

Arjona, A.A., Denbow, D.M. and Weaver, W.D. Jr. 1990. Neonatally induced thermotolerance: Physiological responses. Comp. Biochem. Physiol., 95: 393-399.

Barbosa Filho, J.A.D. 2004. Avaliação do bemestar de aves poedeiras em diferentes sistemas de produção e condições ambientais, utilizando análise de imagens. Dissertação (Mestrado) Física do Ambiente Agrícola. Universidade de São Paulo. Piracicaba. 140 pp.

Barbut, S. 2002 Meat color and flavor. In: Barbut, S. Poultry products processing: An industry guide. Chap.13. CRC. New York. pp. 429-463.

Barnwell, R. e Rossi, A. 2003. Maximização da performance em períodos quentes. Avicultura Industrial, 11: 72-80.

Basilio, V., Vilariño, M., Yahav, S. and Picard, M. 2001. Early age thermal conditioning and a dual feeding program for male broilers challenged by heat stress. Poultry Sci., 80: 29-36.

Basilio, V., Requena, F., León, A., Vilariño, M. and Picard, M. 2003. Earl age thermal conditioning immediately reduces body temperature of broiler chicks in a tropical environment. Poultry Sci., 82: 1235-1241.

Bianchi, M., Petracci, M., Sirri, F., Folegatti, E., Franchini, A. and Meluzzi, A. 2007. The influence of the season and market class of broiler chickens. Poultry Sci., 86: 959-963.

Borges, S.A., Maiorka, A., Silva, A.V.F. 2003. Fisiologia do estresse calórico e a utilização de eletrólitos para frangos de corte. Ciên. Rural, 33: 975-998.

Brossi, C., Shirahigue, L.D., Golineli, B., Contreras,
C.J.C. e Villanueva, N.D.M. 2007. Oxidação lipídica em carne de frango exposto a estresse térmico severo pré-abate. Congresso Brasileiro de Ciência e Tecnologia de Carnes, 4. Centro de Pesquisa e Desenvolvimento de Carnes. Instituto de Tecnologia de Alimentos. Campinas. 1: 231-233.

Brossi, C., Contreras-Castillo, C.J., Amazonas, E.A. e Menten, J.F.M. 2009. Estresse térmico durante o pré-abate em frangos de corte. Ciên. Rural [Online], 39: 1284-1293 (20/03/09).

Cahaner, A. and Leenstra, F. 1992. Effects of high temperature on growth and efficiency of male and female broilers from lines selected for high weight gain, favorable feed conversion, and high or low fat content. Poultry Sci., 71: 12371250.

Classen, H.L. 2000. Managing metabolic disease in rapidly growing strains of poultry. In: Hill, W.G. et al. The challenge of genetic change in animal production. J. Brit. Soc. Anim. Sci. (Occasional publication), 27: 63-64.

Cobb. 2008. Manual de manejo de frangos de corte. Cobb-Vantress. 64 pp.

Collin, A., Berri, C., Tesseraud, S., Requena Rodo'N, F.E., Skiba-Cassy, S., Crochet, S., Duclos, M.J., Rideau, N., Tona, K., Buyse, J., Bruggeman, V., Decuypere, E., Picard, M. and Yahav, S. 2007. Effects of thermal manipulation during early and late embryogenesis on thermotolerance and breast muscle characteristics in broiler chickens. Poultry Sci., 86: 795-800.

Contreras-Castillo, C.J. 2001. Qualidade de carcaça e carne de aves. I Congresso Brasileiro de Ciência e Tecnologia de Carne. 22-25 de Outubro. Anais... São Pedro. pp. 160-178.

Dröge, W. 2002. Free radicals in the physiological control of cell function. Physiol. Revi., 82: 4795.

Essing, D. A. and Nosek, T. M. 1997. Muscle fatigue and indution of stress protein genes: A dual function of reactive oxygen species? Can. J. Appl. Physiol., 22: 409-428.

Fabricio, J.R. 1994. Influência do estresse calórico no rendimento da criação de frangos de corte. Conferência Apinco de Ciência e Tecnologia Avícola, Santos. Anais... Facta Campinas. pp. 129-136.

Fehrenbach, E. and Niess, A.M. 1999. Role of heat shock proteins in the exercise response. 


\section{PROTEÍNA DE CHOQUE TÉRMICO E O ESTRESSE TÉRMICO EM FRANGOS}

Exercise Immunol. Rev., 5: 57-77.

Figueiredo, D.F. 2006. Efeito do estresse sobre a expressão de HSP70 em embriões e a resposta imune pós-eclosão em frangos de corte. Tese (Doutorado Em Zootecnia). Universidade Estadual Paulista Julio de Mesquita Filho. Jaboticabal. 97 pp.

Figueiredo, D., Gertler, A., Cabello, G., Decuypere, E., Buyse, J., Dridi, S. 2007. Leptin downregulates. Heat shock protein-70 (HSP-70) gene expression in chicken liver and hypothalamus. Cell Tissue Res., 329: 91-101.

Fink, A.I. 1999. Chaperone-mediated protein folding. Physiol. Rev., 79: 425-449.

Fletcher, D.L. 2002. Poultry meat quality. World's Poultry Sci. J., 58: 131-145.

Franco-Jimenez, D.J. and Beck, M.M. 2007. Physiological changes to transient exposure to heat stress observed in laying hens. Poultry Sci., 86: 538-544.

Furlan, R.L. and Macari, M. 2002. Termorregulação. In: Fisiologia aviária aplicada a frangos de corte. Cap. 17. Funep/Unesp. Jaboticabal. pp. 209230.

Gabriel, J.E. 2001. Estudo da expressão temporal e especial de genes associados a miogênese durante o desenvolvimento embrionário de aves. Tese (Doutorado). Centro de Energia Nuclear na Agricultura. Universidade de São Paulo, Piracicaba. 118 pp.

Hernandes, R., Ferro, J.A., Gonzales, E., Macari, M., Bernal, F.E.M. e Ferro, M.I.T. 2002. Resistência à síndrome ascítica, competência homeotérmica e níveis de HSP70 no coração e pulmão de frangos de corte. Rev. Bras. Zootecn., 31: 1442-1450.

Holm, C.G.P. and Fletcher, D.L. 1997. Antemortem holding temperatures and broiler breast meat quality. J. Appl. Poultry Res., 6: 180-184.

Kiang, J.G., Tsokos, G.C. 1998. Heat shock protein 70 Kda: Molecular biology, biochemistry, and physiology. Pharmacol. Therapeut., 80: 183201.

Lagana, C. 2005. Otimização da produção de frangos de corte em estresse por calor. Tese (Doutorado em Zootecnia). Universidade do Rio Grande do Sul. Porto Alegre. 180 pp.

Lee, Y.J. 1992. Differential relocalization of each member of HSP70 and HSP28 families during chronic heating. J. Therm. Biol., 17: 161-168.
Liew, P.K., Zulkifli, I., Hair-Bejo, M., Omar, A.R. and Israf, D.A. 2003. Effects of early age feed restriction and heat conditioning on heat shock protein 70 expression, resistance to infectious bursal disease, and growth in male broiler chickens subjected to heat stress. Poultry Sci., Ithaca, 82: 1879-1885.

Lin, H., Jiao, H.C., Buyse, J. and Decuypere, E. 2006. Strategies for preventing heat stress in poultry. World's Poultry Sci. J., 62: 71-86.

Lin, H., Du, R. and Zhang, Z. Y. 2000. Peroxide status in tissues of heat-stressed broilers. Asian Austr. J. Anim. Sci., 13: 1373-1376.

Locke, M. and Noble, E.G.1995. Stress proteins: The exercise response. Can. J. Appl. Physiol., 20: 155-167.

Lu, Q., Wen, J. and Zhang, H. 2007. Effect of chronic heat exposure on fat deposition and meat quality in two genetic types of chicken. Poultry Sci., 86: 1059-1064.

Macari, M., Furlan, R.L. e Maiorka, A. 2004. Aspectos fisiológicos e de manejo para a manutenção da homeostase térmica e controle de síndromes metabólicas. In: Produção de Frangos de Corte. Cap. 9. Facta. Campinas. pp. 137-155.

Mahmoud, K.Z. and Edens, F.W. 2003. Influence of selenium sources on age related and mild heat stress-related changes of blood and liver glutathione redox cycle in broiler chickens (Gallus domesticus). Comp. Biochem. Physiol. B: Biochem. Mol. Biol., 136: 921-934.

Mccurdy, R.D., Barbut, S. and Quinton, M. 1996. Seasonal effect on pale soft exudative (PSE) occurrence in young turkey breast meat. Food Res. Int., 29: 363-366.

Mckee, S.R. and Sams, A.R. 1998. Rigor mortis development at elevated temperatures induces pale exudative turkey meat characteristics. Poultry Sci., 77: 169-174.

Meyer, T.N. and da Silva, A.L. 1999. Resposta celular ao estresse. Rev. Ass. Med. Brasil, 45: 181-188.

Morimoto, Ri., Tissières, A. and Georgopoulos, C. 1994. Progress and perspectives on the biology of heat shock proteins and molecular chaperones. In: Morimoto R.I., Tissières A., Georgopoulos C. The biology of heat shock proteins and molecular chaperones. Cold Spring Harbor Laboratory Press. New York. pp. 1-30. Moseley, P. 2000. Stress proteins and the immune 
response. Immunopharmacology, 48: 299-302. Nääs, I.A. 1997. Ventilação e climatização para frangos de corte. Conferência Apinco 1997 de Ciências e Tecnologias Avícolas. Anais... São Paulo. pp. 108-119.

Offer, G. and Knight, P. 1988. The structural basis of water holding in meat. Part 2: Drip losses. In: Lawrie, R. (Ed.). Developments in Meat Science4. Elsevier Applied Science. London. pp. 172243.

Oliveira, R.F.M., Donzele, J.L., Abreu, M.L.T., Ferreira, R.A., Vaz, R.G.M.V. e Cella, P.S. 2006. Efeitos da temperatura e da umidade relativa sobre o desempenho e o rendimento de cortes nobres de frangos de corte de 1 a 49 dias de idade. Rev. Bras. Zootecn., 35: 797-803.

Oliveira Neto, A.R., Oliveira, R.F.M., Donzele, J.L., Rostagno, H.S., Ferreira, R.A., Maximiano, H.C. e Gasparino, E. 2000. Efeito da temperatura ambiente sobre o desempenho e características de carcaça de frangos de corte alimentados com dieta controlada e dois níveis denergia metabolizável. Rev. Bras. Zootecn., 29: 183190.

Parsell, D.A. and Lindquist, S. 1994. Heat shock proteins and stress tolerance. In: Morimoto, R.I., Tissières, A. and Georgopoulos, C. The biology of heat shock proteins and molecular chaperones. Cold Spring Harbor Laboratory Press. New York. pp. 457-494.

Petracci, M., Fletcher, D.L. and Northcutt, J.K. 2001. The effect of holding temperature on live shrink, processing yield, and breast meat quality of broiler chickens. Poultry Sci., 80: 670-675.

Pough, F.H., Janis, C.M. e Heiser, J.B. 2009. Hoemostase e energia: equilíbrio de água, regulação da temperatura e uso de energia. In: A vida dos vertebrados. $2^{\mathrm{a}}$ ed. Cap. 4. Editora Atheneu SP. São Paulo. pp. 123-159.

Rosemberg, N.J. 1974. Microclimate: the biological envioronment. Hohn Wiley e Sons. New York. $315 \mathrm{pp}$.

Sahin, K., Sahin, N., Onderci, M., Gursu, F. and Cikim, G. 2002. Optimal dietary concentration of chromium for alleviating the effect of heat stress on growth, carcass qualities, and some serum metabolites of broiler chickens. Biol. Trace Element Res., 89: 53-64.

Salvador, D., Ariki, J., Borges, S.A., Pedroso, A.A. e Moraes, V.M.B. 1999. Suplementação de bi- carbonato de sódio na ração e na água de bebida de frangos de corte submetidos ao estresse calórico. Ars Vet., 15: 144-148.

Sandercock, D.A., Hunter, R.R., Nute, G.R., Hocking, P.M. and Mitchel, M.A. 1999. Physicological responses to acute heat stress in broilers: implications for meat quality? European Symposium on the Quality of Poultry Meat, 14. Proceedings... Bologna. pp. 271-276. Sandercock, D.A., Hunter, R.R., Nute, G.R., Mitchell, M.A. and Hocking, P.M. 2001. Acute heat stressinduced alterations in blood acid-base status and skeletal muscle membrane integrity in broilers chickens at two ages: implications for meat quality. Poultry Sci., 80: 418-425.

Smith, C.V.A. 1964. Quantitative relationship between environment, confort and animal productivity. Agric. Meterol., 1: 249-270.

Terlouw, C. 2004. Stress reactions at slaughter and meat quality in pigs: genetic background and prior experience, a brief review of recent findings. Livest. Prod. Sci., 37: 91-98.

Tinôco, I.F.F. 2001. Ambiência na produção de matrizes avícolas. Ambiência na produção de aves em clima tropical. Funed. Piracicaba-Sp. 2: 1-43.

Tinôco, I.F.F. 2004. A granja de frangos de corte. In: Produção de Frangos de Corte. Cap. 4. Facta. Campinas. pp. 55-84.

Vercellotti, J.R., St. Angelo, A.J. and Spanier, A.M. 1992. Lipid oxidation in foods: an overview. In: St. Angelo. Lipid oxidation in food. American Chemical Society. Washington. pp. 1-11.

Welch, W.J. 1992. Mammalian stress response: cell physiology, structure/function of stress proteins, and implications for medicine and disease. Physiol. Rev., 72: 1063-1081.

Woelfel, R.L., Owens, C.M., Hirschler, E.M., Martinez-Dawson, R. and Sams, A.R. 2002. The characterization and incidence of pale, soft and exudative broiler meat in a commercial processing plant. Poultry Sci., 81: 579-584.

Woelfel, R.L. and Sams, A.R. 2001. Marination performance of pale broiler breast meat. Poultry Sci., 80: 1519-1522.

Yahav S. 2000. Domestic fowl. Strategies to confront environmental conditions. Avian Poult. Rev., 11: 81-95.

Yahav, S. and Hurwitz, S. 1996. Introduction of thermotolerance in male broiler chickens by 


\section{PROTEÍNA DE CHOQUE TÉRMICO E O ESTRESSE TÉRMICO EM FRANGOS}

temperature conditioning at an early age. Poultry Sci., 75: 402-406.

Yahav, S, Shamay, A., Horev, G., Bar-llan, D., Genina, O. and Friedman-Einat, M. 1997. Effect of acquisition of improved thermotolerance on the induction of heat shock proteins in broiler chickens. Poultry Sci., 76: 1428-1434.

Zulkifli, I., Che Norma, M.T., Israf, D.A. and Omar, A.R. 2000. The effect of early age feed restriction on subsequent response to high environmental temperatures in female chickens. Poultry Sci., 79: 1401-1407. 